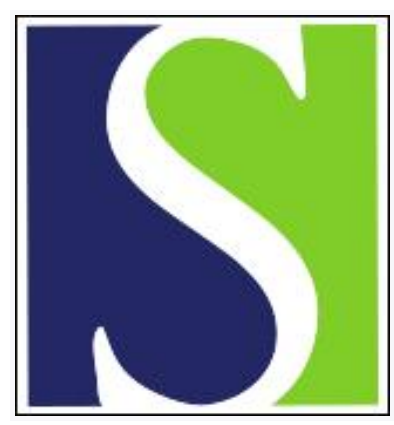

Scand J Work Environ Health 1988;14(4):246-251

https://doi.org/10.5271/sjweh.1925

Issue date: Aug 1988

Risk of non-Hodgkin's lymphoma among men occupationally exposed to organic solvents.

by Olsson $\mathrm{H}$, Brandt L

Affiliation: Department of Oncology, University Hospital, Lund, Sweden.

This article in PubMed: www.ncbi.nlm.nih.gov/pubmed/3175557

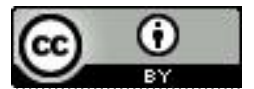




\title{
Risk of non-Hodgkin's lymphoma among men occupationally exposed to organic solvents
}

\author{
by Håkan Olsson, MD, Lars Brandt, $\mathrm{MD}^{1}$
}

\begin{abstract}
OLSSON H, BRANDT L. Risk of non-Hodgkin's lymphoma among men occupationally exposed to organic solvents. Scand J Work Environ Health 14 (1988) 246-251. An occupational history of exposure to organic solvents, defined as daily occupational exposure for at least one year, was more common among 167 men with newly diagnosed non-Hodgkin's lymphoma than among 130 healthy referents from the general population (38 versus $14 \%$ ). Categorization in five-year age groups gave 3.3 as a Mantel-Haenszel estimate of the odds ratio $(95 \%$ CI $1.9-5.8)$. The odds ratio was 6.5 (95\% CI 3.2-13.3) for localized supradiaphragmatic tumors and $2.3(95 \%$ CI 1.3-4.3) for other lymphoma presentations. In a logistic model including age and organic solvent, phenoxy acid, and chlorophenol exposure, it could be shown that solvent exposure was an independent risk factor and that no important interaction occurred between the risk factors. With increasing duration of exposure there was a significantly increased risk of lymphoma, a finding implying a dose-response relationship. There was no significant difference in tumor histology between the exposed and unexposed patients. These findings support the concept that occupational exposure to organic solvents is a risk factor for non-Hodgkin's lymphoma. The results also confirm a strong association between such exposure and an initial supradiaphragmatic location of the lymphomas.
\end{abstract}

Key terms: case-referent study, chlorophenols, phenoxy acids, skin lymphoma, supradiaphragmatic location of lymphoma.

Occupational exposure to organic solvents may be a risk factor for the development of Hodgkin's disease $(2,8,16,17,22)$. There are also indications that nonHodgkin's lymphoma may be related to such exposure $(8,22,24,25)$, and in preliminary studies we found that a history of occupational exposure to solvents may be especially common among patients with an initial supradiaphragmatic location of the disease $(18,20)$.

To explore the possible association between exposure to solvents and the development of non-Hodgkin's lymphoma further, we have compared the occupational histories obtained from a consecutive series of male non-Hodgkin's lymphoma patients with the corresponding information obtained from a reference group of healthy men. We also considered it important to investigate whether an association between occupational exposure to solvents and a supradiaphragmatic location might be confirmed.

\section{Subjects and methods}

\section{Patients with non-Hodgkin's lymphoma}

A consecutive series of 167 adult men with nonHodgkin's lymphoma admitted to our department in 1978-1981 was studied. The median age was 57 (range $20-81$ ) years. In this period approximately $70 \%$ of the non-Hodgkin's lymphoma patients aged 16 to 70

\footnotetext{
1 Department of Oncology, University Hospital, Lund, Sweden.
}

Reprint requests to: Dr H Olsson, Department of Oncology, University Hospital, S-221 85 Lund, Sweden. years and diagnosed in the southern health care region of Sweden were referred to the department, whereas the referral rate for patients over 70 years of age was about $40 \%$.

Representative tumor material was obtained from all patients and classified according to Rappaport (21). Clinical staging was performed according to the Ann Arbor classification (4). In addition to clinical stage an initial supradiaphragmatic location of non-Hodgkin's lymphoma was recorded separately. Localized skin lymphoma was also considered because such lesions may be especially related to exposure to herbicides $(19,20)$.

\section{Interviews and definition of exposure}

All the patients were interviewed personally by one of us $(\mathrm{HO})$ using a standardized questionnaire. No patient declined an interview. A lifetime occupational history was recorded as described previously (18). Exposure to organic solvents, phenoxy acids, and chlorophenols was given special attention. Patients who had occupationally handled organic solvents for at least one year daily were classified as exposed. Those who had handled phenoxy acids or chlorophenols occupationally for at least $1 \mathrm{~d}$ were considered exposed to these agents.

\section{Referents}

Two groups of healthy men were selected from the population register as referents. Group A comprised 50 men who also served as age-matched referents in 
a case-referent study of Hodgkin's disease. This group was recruited from the same geographic area as the non-Hodgkin's lymphoma patients. Their median age was 47 (range 18-77) years. The referents in this group were interviewed by one of us (HO). All the referents accepted the interview.

Group B consisted of 90 men with a median age of 56 (range 17-78) years from different parts of Sweden. They were selected as referents in a casereferent study of soft-tissue sarcoma. Ten referents from this group refused the interview or could not be contacted. One-fourth of the remaining 80 referents were residents in the same geographic area as the nonHodgkin's lymphoma patients. The referents in this group were interviewed by two trained interviewers, neither of which was one of the authors.

The questionnaire used for the referents in groups $A$ and $B$ was the same as that used for the patients with non-Hodgkin's lymphoma. In all the interview situations the interviewee was known as a case or a referent.

\section{Statistical methods}

Odds ratios were calculated according to Miettinen (10). With the use of Mantel-Haenszel's test, a chisquare test was computed, and summary odds ratios for five-year age groups were calculated with the $95 \%$ confidence interval $(95 \% \mathrm{CI})$. For the univariate odds ratios the test-based confidence interval by Miettinen was used.

To study the simultaneous effect of solvent exposure, phenoxy herbicide exposure, and chlorophenol exposure on the risk of lymphoma, we used a logistic model adjusted for age and possible interaction between the exposures. The possible associations between solvent exposure and a supradiaphragmatic tumor location $(18,20)$ and between phenoxy herbicide exposure and localized skin lymphoma $(19,20)$ were also studied in separate logistic models. The possible impact of duration of solvent, herbicide, and chlorophenol exposure on the risk for non-Hodgkin's lymphoma was also investigated in separate logistic models. For the multivariate analyses of the odds ratios, the standard error of the maximum likelihood estimate was used to calculate the confidence intervals.

There was no difference in solvent exposure between the two reference groups $\left(\mathrm{X}^{2}=0.19\right.$, NS). Nor was there any appreciable difference between the two groups regarding exposure to herbicides or chlorophenols. Thus, for practical purposes, groups $\mathbf{A}$ and $\mathrm{B}$ were combined in the analyses.

\section{Results}

Daily occupational exposure to organic solvents for at least one year was reported by $38 \%$ of the cases and $14 \%$ of the referents.

In table 1 solvent exposure is shown for the reference groups and the cases in five-year age categories. The patients with non-Hodgkin's lymphoma were more often exposed to solvents than the referents $\left(\mathrm{X}^{2}=17.7, \mathrm{P}=\mathbf{0 . 0 0 0 1}\right.$, Mantel-Haenszel estimate for five-year age categories). The corresponding odds ratio was 3.3 (95 \% CI 1.9-5.8).

Fifty-five patients had localized supradiaphragmatic lymphoma (table 2). The Mantel-Haenszel odds ratio for this group of lymphoma patients was 6.5 (95\% CI 3.2-13.3). In 112 other patients the lymphomas were localized below the diaphragm, or the disease was generalized. This group had a lower odds ratio of $\mathbf{2 . 3}$ (95 \% CI 1.3-4.3).

In table 3 the relationship between solvent, phenoxy acid, and chlorophenol exposure on the risk for lymphoma is given by different logistic models. As can be seen, solvent exposure was an independent risk factor of lymphoma when the model was adjusted for age and the other factors (odds ratio 2.0). No important interaction was evident between the risk factors. The highest risk was seen for patients with supradiaphragmatic tumor location (odds ratio 3.4). An increased odds ratio was seen for other lymphoma locations, but the risk was substantially lower (odds ratio 1.4). Neither phenoxy acid exposure nor chlorophenol ex-

Table 1. Number of patients with non-Hodgkin's lymphoma and referents with daily solvent exposure for at least one year according to year of birth.

\begin{tabular}{|c|c|c|c|c|c|c|}
\hline \multirow{3}{*}{ Year of birth } & \multirow{2}{*}{\multicolumn{2}{|c|}{ Patients }} & \multicolumn{4}{|c|}{ Referents } \\
\hline & & & \multicolumn{2}{|c|}{ Group A } & \multicolumn{2}{|c|}{ Group B } \\
\hline & Exposed & Unexposed & Exposed & Unexposed & Exposed & Unexposed \\
\hline-1955 & 2 & 1 & 0 & 4 & 2 & 10 \\
\hline $1950-1954$ & 0 & 2 & 3 & 3 & 0 & 0 \\
\hline $1945-1949$ & 6 & 3 & 0 & 6 & 2 & 9 \\
\hline $1940-1944$ & 5 & 5 & 1 & 7 & 2 & 6 \\
\hline $1935-1939$ & 6 & 4 & 0 & 0 & 0 & 0 \\
\hline $1930-1934$ & 5 & 11 & 2 & 10 & 0 & 0 \\
\hline $1925-1929$ & 2 & 8 & 0 & 2 & 0 & 9 \\
\hline $1920-1924$ & 11 & 18 & 0 & 6 & 2 & 12 \\
\hline $1915-1919$ & 7 & 14 & 0 & 2 & 1 & 14 \\
\hline $1910-1914$ & 8 & 15 & 0 & 2 & 3 & 4 \\
\hline $1910-$ & 11 & 23 & 0 & 2 & 0 & 4 \\
\hline
\end{tabular}


Table 2. Tumor location in relation to year of birth and exposure of the patients to organic solvents.

\begin{tabular}{lcccc}
\hline \multirow{2}{*}{ Year of birth } & \multicolumn{2}{c}{ Supradiaphragmatic location } & \multicolumn{2}{c}{ Others } \\
\cline { 2 - 5 } & Exposed & Unexposed & Exposed & Unexposed \\
\hline 1955 & 0 & 1 & 2 & 0 \\
$1950-1954$ & 0 & 0 & 0 & 2 \\
$1945-1949$ & 5 & 0 & 2 & 3 \\
$1940-1944$ & 3 & 0 & 2 & 5 \\
$1935-1939$ & 4 & 2 & 2 & 9 \\
$1930-1934$ & 3 & 0 & 2 & 8 \\
$1925-1929$ & 0 & 8 & 5 & 10 \\
$1920-1924$ & 4 & 3 & 5 & 11 \\
$1915-1919$ & 3 & 2 & 4 & 13 \\
$1910-1914$ & 7 & 6 & 2 & 17 \\
$1910-$ & 3 & & 2 & 2 \\
\hline
\end{tabular}

Table 3. Risk of lymphoma related to exposure to solvents, herbicides and chlorophenols and to the site of tumor location, calculated with different multivariate models. $(95 \% \mathrm{Cl}=$ $95 \%$ confidence interval)

\begin{tabular}{lcc}
\hline Exposure & Odds ratio & $95 \% \mathrm{Cl}$ \\
\hline $\begin{array}{l}\text { Model I } \\
\quad \text { Solvents (all patients) }\end{array}$ & 2.0 & $1.5-2.6$ \\
$\quad \begin{array}{l}\text { Herbicides (all patients) } \\
\text { Chlorophenols (all patients) }\end{array}$ & 1.3 & $0.8-2.1$ \\
$\begin{array}{l}\text { Model II } \\
\quad \text { Solvents (supradiaphragmatic) }\end{array}$ & 3.4 & $0.7-2.0$ \\
$\quad \begin{array}{l}\text { Chlorophenols (supra- } \\
\text { diaphragmatic) }\end{array}$ & 1.7 & $0.7-4.2$ \\
$\begin{array}{l}\text { Model III } \\
\quad \text { Solvents (infradiaphragmatic } \\
\text { or generalized) }\end{array}$ & 1.4 & $1.0-2.0$ \\
Model IV \\
$\quad \begin{array}{l}\text { Herbicides } \\
\text { involvement) }\end{array}$ \\
\hline
\end{tabular}

a Adjusted for age and the risk factors simultaneously. No sig. nificant interaction was seen.

b Herbicides $=$ phenoxy acid exposure.

Table 4. Exemplified risk of lymphoma in relation to duration of solvent exposure. ( $95 \% \mathrm{Cl}=95 \%$ confidence interval)

\begin{tabular}{lcc}
\hline Difference in length of exposure & Odds ratio & $95 \% \mathrm{Cl}$ \\
\hline 120 months & 1.8 & $1.2-2.7$ \\
240 months & 3.3 & $1.5-7.1$ \\
360 months & 6.0 & $1.9-19.0^{*}$ \\
\hline
\end{tabular}

$* \mathrm{P}<0.001$.

Table 5. Histopathology in relation to exposure to organic solvents. Classification according to that of Rappaport transformed to the working formulation classification (26).

\begin{tabular}{lrrrrrr}
\hline \multirow{2}{*}{ Histopathology } & \multicolumn{2}{c}{ Exposed } & & \multicolumn{2}{c}{ Unexposed } \\
\cline { 2 - 3 } \cline { 6 - 7 } \cline { 6 - 7 } & $\mathrm{N}$ & $\%$ & & $\mathrm{~N}$ & $\%$ \\
\hline Low grade & 13 & 21 & & 29 & 28 \\
Intermediate grade & 18 & 29 & & 36 & 35 \\
High grade & 27 & 43 & & 33 & 32 \\
Lennert lymphoma & 3 & 5 & & 0 & 0 \\
Angioimmunoblastic & 1 & 2 & & 3 & 3 \\
lymphadenopathy & 0 & 0 & & 2 & 2 \\
Sezary syndrome & 1 & 2 & & 1 & 1 \\
Unclassified & & & & & &
\end{tabular}

posure was significantly related to lymphoma risk. However, for localized skin lymphoma, a significant risk was seen for phenoxy acid exposure (odds ratio 10.0)

The duration of exposure was $1-47$ (median 10) years. The latency time from the start of exposure to the diagnosis of non-Hodgkin's lymphoma was 2-60 (median 21) years. The risk of lymphoma increased with the duration of solvent exposure, and therefore a dose-response relationship, logistic regression $(\mathrm{P}<0.001)$ was implied (table 4$)$. No evidence of a dose-response relationship was seen for the herbicide exposure or the chlorophenol exposure.

There was no significant difference in histopathology between the lymphoma patients with and without exposure to solvents (table 5). The age at diagnosis was slightly lower for the exposed patients (median 54 years) than the unexposed patients (median 58 years), but the difference was not significant.

A variety of occupations was associated with exposure to solvents. Thus employment in the operation or repair of machines accounted for $20 \%$, work in the chemical industry or as a chemist for $16 \%$, work as a painter for $14 \%$, work in the wood or furniture industry for $11 \%$, printing work for $9 \%$, employment in the rubber or plastics industry for $6 \%$, shoe manufacturing for $4 \%$, cleaning work for $3 \%$, and biological work for $3 \%$ of the number of exposure events. Occasionally work in the metal industry, building industry, transport service, retail trade, or military employment was associated with solvent exposure.

\section{Discussion}

The results of this study suggest that occupational exposure to organic solvents may be a risk factor for nonHodgkin's lymphoma. Moreover, the association with such exposure was found to be especially strong for non-Hodgkin's Iymphoma patients with a supradiaphragmatic location of the disease.

A recall bias regarding exposure must be considered possible in a case-referent study with the present design. To reduce this possibility, we defined exposure as a fairly long period, ie, one year, of handling sol- 
vents daily. Certain data indicate that recall bias was not of crucial importance for the present results. Thus there was a remarkable difference in exposure reported by the non-Hodgkin's lymphoma patients with a supradiaphragmatic tumor location and that reported by those with other initial locations. There were no obvious reasons for some non-Hodgkin's lymphoma patients recalling a long period of exposure more often than other patients with the same disease.

All the patients and all the referents in group A were residents in the southern health care region of Sweden, whereas the majority of the referents in group B lived in other parts of the country. Due to the geographic differences exposure to various chemical hazards might be different in the two reference groups. However, the proportions of referents exposed to solvents, herbicides, or chlorophenols were very similar in the two groups, and we therefore considered it justified to combine them into one group of referents in the analyses. The patients and the referents in group A were interviewed by one person, whereas those in reference group B were interviewed by two other persons. Although a standardized schedule was followed in all the interviews, it is possible that different interviewers may obtain different information. However, the exposure data obtained from reference groups A and B were strikingly similar, and it is therefore unlikely that the information on exposure obtained by the different interviewers differed systematically.

One disadvantage with the personal interviews used in the present study was the fact that the interviewer was aware of whether the interviewee was a patient or a referent. The use of written questionnaires analyzed blindly might have reduced this potential bias. On the other hand the use of such a design in a study group of patients with a relatively high median age may have disadvantages. Information may often be incomplete and necessitate a supplementary personal interview of some patients and referents. In the present material the quality of the information obtained in the personal interviews may thus outweigh the potential bias inherent in this method.

The present results confirm our preliminary finding that previous occupational exposure to organic solvents is especially common among patients with an initial location of lymphoma above the diaphragm (18, 20 ). Thus the crude odds ratio for these patients was 6.5 compared with 2.3 for patients with subdiaphragmatic or generalized lymphomas. When age and other risk factors were adjusted for, the odds ratios were 3.4 and 1.4, respectively. As proposed previously (18), one reason for a supradiaphragmatic presentation of nonHodgkin's lymphoma in patients handling solvents may be that these volatile agents cause a considerable exposure of the mucous membranes in the upper and lower respiratory tract. Lymphoid tissue in these areas is probably exposed to higher concentrations of the substances than such tissue in other parts of the body. It therefore seems reasonable that initial malignant transformation should be observed in lymphoid tissue above the diaphragm rather than in such tissue located elsewhere.

A great variation in the duration of exposure, $1-47$ years, was recorded for the non-Hodgkin's lymphoma patients, and there was a relation between the duration of occupational exposure and the risk of nonHodgkin's lymphoma. This finding implies a doseresponse relation between exposure to solvents and the risk of developing non-Hodgkin's lymphoma. However assessing the duration of exposure might not fully describe the extent of the exposure because the environmental concentrations of solvents are unknown. Moreover, a daily handling of solvents for one year was required for a classification as exposed, and shorter periods of exposure might well be hazardous. In future investigations also shorter periods of exposure than in the present study should therefore be considered.

There were large variations in the length of periods from the start of exposure to the diagnosis of nonHodgkin's lymphoma, 2-60 years with a median of 21 years. Because the putative malignant transformation caused by solvent exposure may have occurred at any time during the period of exposure, the average latency time from tumor initiation to clinical manifestation should be less than 21 years. This assumption is in concordance with observations of nonHodgkin's lymphoma after exposure to ionizing radiation (14). The excess risk of non-Hodgkin's lymphoma did not appear until 14-16 years after such exposure. It appears that the average latency time for the development of non-Hodgkin's lymphoma in association with environmental hazards is longer than for acute leukemia caused by similar agents. Thus, in patients with acute leukemia following exposure to benzene, the average latency time from the start of exposure to diagnosis seems to be about 10 years $(1,23)$, and acute leukemia following exposure to therapeutic irradiation and chemotherapy is usually seen $2-12$ years after such treatment (3). The average latency time from the start of exposure to solvents until diagnosis may also be longer for non-Hodgkin's lymphoma than for Hodgkin's disease. In a previous study (17) we found the corresponding time to average 10.5 years for patients with Hodgkin's disease following occupational exposure to solvents. Despite the great variations observed the latency times for the development of malignancies affecting the hematopoietic and lymphatic systems may be relatively short when compared with those for other tumors related to environmental hazards. In epidemiologic studies of leukemias and lymphomas it may therefore be important to include cases with a relatively recent exposure to suspected etiologic agents.

In previous epidemiologic studies of the relation between solvent exposure and the development of malignant lymphoma, it has been impossible to define the agent(s) which are especially hazardous. This failure is due to the fact that almost invariably multiple organic solvents have been handled by the exposed pa- 
tients and referents $(13,17,22)$. As expected, the same problem was encountered in the present study, and we cannot therefore make any risk assessment for any specific solvent used.

Occupational handling of phenoxy acids, suspected as a risk factor for non-Hodgkin's lymphoma (8), was not a confounding factor in the present study. Thus, in a multivariate analysis, solvent exposure was an independent risk factor, and there was no interaction between solvent exposure, herbicide exposure, or chlorophenol exposure. Moreover there was no association between supradiaphragmatic location of the lymphoma and exposure to herbicides, whereas isolated skin lymphomas were associated with such exposure.

No particular morphologic type of lymphoma was predominant in the exposed patients. This finding is analogous to those for acute leukemias. Thus Aksoy et al (1) found various morphological subtypes of acute leukemia following benzene exposure. Despite the heterogeneous morphological pattern there are indications that the lymphomas in patients occupationally exposed to solvents may have some properties in common. Certain chromosome aberrations in lymphoma cells from exposed non-Hodgkin's lymphoma patients are more common than in lymphoma cells from patients without any history of exposure to solvents (Brandt et al, submitted for publication). These findings are also analogous to results of chromosome studies with patients with acute nonlymphocytic leukemia and a history of exposure to potentially mutagenic chemicals $(6,11,12$, 27).

In the present study there was a relative underrepresentation of patients above the age of 70 years. The risk assessments calculated may therefore be less reliable for the oldest age groups. Nevertheless our results support the concept that occupational exposure to organic solvents may be hazardous with regard to non-Hodgkin's lymphoma. Because such exposure may also be relevant for the development of other malignant disorders of hematopoietic and lymphatic tissue $(1,2,5,7,8,9,15,16,23,25)$, our data support the opinion that occupational exposure to organic solvents should be minimized.

\section{Acknowledgments}

This study was supported by a grant from the Swedish Cancer Society and Lund's sjukvårdsdistrikt.

\section{References}

1. Aksoy M, Erdem S, Dincol G. Types of leukemia in chronic benzene poisoning: A study in thirty-four patients. Acta Haematol 55 (1976) 65-72.

2. Aksoy M, Erdem S, Dincol K, Hepyüksel T, Dincol G. Chronic exposure to benzene as a possible contributory etiologic factor in Hodgkin's disease. Blut 28 (1974) 293-298.

3. Blayney DW, Longo DL, Young RC, Greene MH, Hubbard SM, Postal MG, Duffey PL, De Vita VT. Decreas- ing risk of leukemia with prolonged follow-up after chemotherapy and radiotherapy for Hodgkin's disease. N Engl J Med 316 (1987) 710-714.

4. Carbone PP, Kaplan HS, Musshof K, Smithers DW, Tubiana M. Report of the committee on Hodgkin's disease staging. Cancer Res 31 (1971) 1860-1861.

5. Flodin U, Andersson L, Anjou C-G, Palm U-B, Vikrot $\mathrm{O}$, Axelson $\mathrm{O}$. A case-referent study on acute myeloid leukemia, background radiation and exposure to solvents and other agents. Scand J Work Environ Health 7 (1981) 169-178.

6. Golomb HM, Alimena G, Rowley JD, Vardiman JW, Testa JR, Sovik C. Correlation of occupation and karyotype in adults with acute non-lymphocytic leukemia. Blood 60 (1982) 404-411.

7. Greene MH, Hoover RN, Eck RL, Fraumeni JF. Cancer mortality among printing plant workers. Environ Res (1979) 66-73.

8. Hardell L, Eriksson M, Lenner P, Lundgren E. Malignant lymphomas and exposure to chemical agents, especially to organic solvents, chlorophenols and phenoxy acids: A case-control study. Br J Cancer 43 (1981) 169-179.

9. Hodgson JT, Jones RD. Mortality of styrene production, polymerization and processing workers at a site in northwest England. Scand J Work Environ Health 11 (1985) 347-352.

10. Miettinen OS. Estimation of relative risk from individually matched series. Biometrics 29 (1970) 75-86.

11. Mitelman F, Brandt L, Nilsson PG. Relation among occupational exposure to potential mutagenic/carcinogenic agents, clinical findings and bone marrow chromosomes in acute non-lymphocytic leukemia. Blood 52 (1978) 1229-1237.

12. Mitelman F, Nilsson PG, Brandt L, Alimena G, Gastaldi R, Dallapiccola B. Chromosome pattern, occupation, and clinical features in patients with acute nonlymphocytic leukemia. Cancer Genet Cytogenet 4 (1981) 197-214.

13. Monson RR, Fine LJ. Cancer mortality and morbidity among rubber workers. J Natl Cancer Inst 61 (1978) 1047-1053.

14. Nishiyama $H$, Andersson RE, Ishimaru $T$. The incidence of malignant lymphoma and multiple myeloma in Hiroshima and Nagasaki atomic bomb survivors 19451965. Cancer 32 (1973) 1301-1309.

15. Oleske D, Golomb HM, Farber MD, Levy PS. A casecontrol inquiry into the etiology of hairy cell leukemia. Am J Epidemiol 121 (1985) 675-683.

16. Olin R, Ahlbom A. The cancer mortality among Swedish chemists graduated during three decades: A comparison with the general population and with a cohort of architects. Environ Res 22 (1980) 154-169.

17. Olsson H, Brandt L. Occupational exposure to organic solvents and Hodgkin's disease in men: A case-referent study. Scand J Work Environ Health 6 (1980) 302-305.

18. Olsson H, Brandt L. Supradiaphragmatic presentation of non-Hodgkin's lymphoma in men occupationally exposed to organic solvents. Acta Med Scand 210 (1981) 415-418.

19. Olsson H, Brandt L. Non-Hodgkin's lymphoma of the skin and occupational exposure to herbicides. Lancet 2 (1981) 579.

20. Olsson H, Brandt L, Gullberg B. Tumour presentation in non-Hodgkin's lymphoma (NHL) in relation to age, sex, histology, heredity and certain occupations. In: 3rd European conference on clinical oncology (ECCO), Stockholm 1985. (Abstract no 745).

21. Rappaport H. Tumours of the hematopoietic system. In: Atlas of tumor pathology, section 3, fascicle 8 . Armed Forces Institute of Pathology, Washington, DC 1966, pp 97-161.

22. Vianna NJ, Polan A. Lymphomas and occupational benzene exposure. Lancet 1 (1979) 1394-1395. 
23. Vigliani EC. Leukemia associated with benzene exposure. Ann NY Acad Sci 271 (1976) 143-151.

24. Woods JS, Polisser L, Severson RK, Heuser LS, Kulander BG. Soft tissue sarcoma and non-Hodgkin's lymphoma in relation to phenoxy herbicide and chlorinated phenol exposure in Western Washington. J Natl Cancer Inst 78 (1987) 899-910.

25. Zoloth SR, Michaels DM, Villalbi JR, Lacher M. Patterns of mortality among commercial pressmen. J Natl Cancer Inst 76 (1986) $1047-1051$.

26. - National Cancer Institute sponsored study of classification of non-Hodgkin's lymphomas: Summary and description of a working formulation for clinical usage. Cancer 49 (1982) 2112-2135.

27. . Fourth international workshop on chromosomes in leukemia 1982: The correlation of karyotype and occupational exposure to potential mutagenic/carcinogenic agents in acute non-lymphocytic leukemia. Cancer Genet Cytogenet 11 (1984) 326-331.

Received for publication: 10 April 1987 